\title{
Spinal anesthesia in 62 premature, former-prema- ture or young infants-technical aspects and pitfalls
}

\author{
[La rachianesthésie chez 62 enfants prématurés, anciens prématurés ou jeunes \\ enfants - aspects techniques et pièges]
}

Ze'ev Shenkman MD, * David Hoppenstein MB BCH DA(SA), ${ }^{*}$ Ita Litmanowitz MD, † Shy Shorer MD, ${ }^{*}$ Michael Gutermacher MD,‡ Ludvig Lazar MD, $\ddagger$ Ilan Erez MD, $\ddagger$ Robert Jedeikin BSc MB CHB FFA, * Enrique Freud MD‡

Purpose: To highlight technical aspects and pitfalls of spinal anesthesia (SA) in infants.

Methods: The medical history and perioperative course of all infants who underwent SA over a 28-month period were collected (retrospectively in the first 20).

Results: Sixty-two infants underwent surgery under SA. Fifty-five were premature and former-premature, postconceptional age 43.3 \pm 5.0 weeks, weight $326 \mathrm{I} \pm 1243 \mathrm{~g}$. Of these, 21 had co-existing disease: cerebral (six), cardiac (nine), pulmonary (I I) and uro-

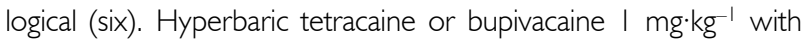
adrenaline was administered. Four infants (three premature) required $\mathrm{N}_{2} \mathrm{O}$ supplementation and three needed general anesthesia. The supplementation rate was similar or lower than in previous studies. Postoperatively, all seven were shown to have lower limb motor and sensory blockade. Complications in premature patients included intraoperative hypoxemia (two), apnea (two) and bradycardia (one). Postoperative complications included bradycardia (three), hypoxemia (one) and apnea and hypoxemia (one). The postoperative complication rate was similar to previous studies.

Conclusion: Successful SA in infants depends on close attention to preoperative assessment, appropriate patient positioning during and after lumbar puncture, drug dosing and intra- and postoperative cardiorespiratory monitoring. A relatively high dose of hyperbaric solution of tetracaine or bupivacaine with adrenaline should be administered.

Objectif : Montrer les aspects techniques et les pièges de la rachianesthésie (RA) chez les enfants.

Méthode : Nous avons noté les antécédents médicaux et le déroulement périopératoire pour tous les enfants qui ont eu une RA au cours de 28 mois (de façon rétrospective pour les 20 premiers).
Résultats : Des 62 enfants qui ont subi une opération avec $R A$, 55 étaient prématurés ou anciens prématurés. L'âge post-fécondation était de 43,3 \pm 5,0 semaines, le poids de $3261 \pm 1243$ g. De ces 55 enfants, 21 avaient une maladie concomitante : cérébrale (six), cardiaque (neuf), pulmonaire (onze) et urologique (six). Une dose de I $\mathrm{mg} \cdot \mathrm{kg}^{-1}$ de tétracaïne ou de bupivacaïne hyperbare, combinée à de l'épinéphrine, a été administrée. Quatre enfants (trois prématurés) ont eu besoin d'un apport complémentaire de $\mathrm{N}_{2} \mathrm{O}$ et trois, d'anesthésie générale. La fréquence d'administration d'un supplément était comparable ou plus faible que celle d'études antérieures. Les sept enfants ont tous présenté un blocage moteur et sensoriel postopératoire des membres inférieurs. Les complications peropératoires notées chez les patients prématurés sont l'hypoxémie (deux), l'apnée (deux) et la bradycardie (un). Les complications postopératoires sont la bradycardie (trois), l'hypoxémie (un) et, l'apnée et l'hypoxémie (un). Ces dernières se comparent à celles d'études antérieures.

Conclusion : Le succès de la RA chez un enfant dépend de la qualité de l'évaluation préopératoire, de l'installation appropriée de l'enfant pendant et après la ponction lombaire, du dosage médicamenteux et du monitorage cardio-respiratoire peropératoire et postopératoire. Une dose relativement élevée de tétracaïne ou de bupivacaïne hyperbare, combinée à de l'épinéphrine, devrait être administrée.

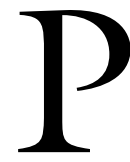

REMATURE infants' survival has increased in recent years and due to co-morbidity more infants may require anesthesia and surgery. ${ }^{1}$ Inguinal hernia is diagnosed in $9-30 \%$ of premature infants ${ }^{2,3}$ with incarceration occurring in up to $31 \%$ of patients. ${ }^{2,4,5}$ However,

From the Departments of Anesthesia and Critical Care Medicine, ${ }^{*}$ Neonatal Intensive Care Unit, $†$ and Pediatric Surgery, $\ddagger$ Meir Hospital, Kfar Saba, Israel, and the Sackler Faculty of Medicine, Tel Aviv University, Tel Aviv, Israel.

Address correspondence to: Dr. Ze'ev Shenkman, Department of Anesthesia and Intensive Care, Meir Hospital, Tshernichovsky Street,

Kfar Saba 44281, Israel. Phone: 972-9-747-1545; Fax: 972-9-742-3233; E-mail: shlomsh@netvision.net.il

Accepted for publication October 29, 2001.

Revision accepted December 17, 2001. 
incarceration and its potential complications ${ }^{2,5,6}$ may be prevented by early surgical repair.

Traditionally, surgical repair was performed under general anesthesia. However, general anesthesia increases the risk of 'postoperative apnea' (breath-holding, hypoxemia, bradycardia, or their combinations) in up to $80 \%$ of premature and former-premature infants. ${ }^{1,7-11}$ The risk of anesthetic-induced 'postoperative apnea' diminishes markedly between 44 and 60 weeks postconceptional age, ${ }^{1,7,11,12}$ but persists longer in older anemic infants. ${ }^{7}$

Spinal anesthesia (SA) may reduce the risk of any of the three components of 'postoperative apnea' in this high- risk group. ${ }^{8,10}$ Its use in premature and other infants has increased considerably since Abajian et al. drew attention to this technique over 15 years ago. ${ }^{13}$ However, technical aspects of the technique and intraoperative complications attributed to SA are rarely mentioned.

We present our experience of SA in premature, former-premature and full-term young infants over a 28 month period. Emphasis is placed on the technical aspects and intraoperative complications associated with SA in this population.

Patients and methods

The medical history and perioperative course of all children who underwent SA at our institution over a 28 - month period were collected. Data of the first 20 patients were reviewed retrospectively. Gestational and postconceptional age, birth and current weight, coexisting disease, hematocrit, and perioperative course were recorded.

\section{Preoperative preparation}

Contra-indications for SA included coagulopathy, local [site of lumbar puncture (LP)] or systemic infection, meningitis, intracranial bleeding, intracranial hypertension, hydrocephalus, presence of a cerebrospinal fluid (CSF) draining device, hypovolemia and spinal deformities.

Diet was unrestricted until six hours preoperatively. Clear fluids were encouraged until three hours before induction. A maintenance $i v$ glucose and electrolyte solution was infused from the start of preoperative fasting in in-patients prior to induction until resumption of enteral feeding after surgery. Patients admitted from home also received iv Hartmann's solution except for those with chronic lung disease. ${ }^{14}$ Ninety minutes prior to surgery, $0.5-1 \mathrm{~mL}$ of EMLA® cream (Astra Sodertalje, Sweden), was applied to the midline area over $\mathrm{L}_{4}-\mathrm{S}_{1}$ and covered with an occlusive dressing (Tegaderm, 3 M Health Care, St. Paul, MN, USA).

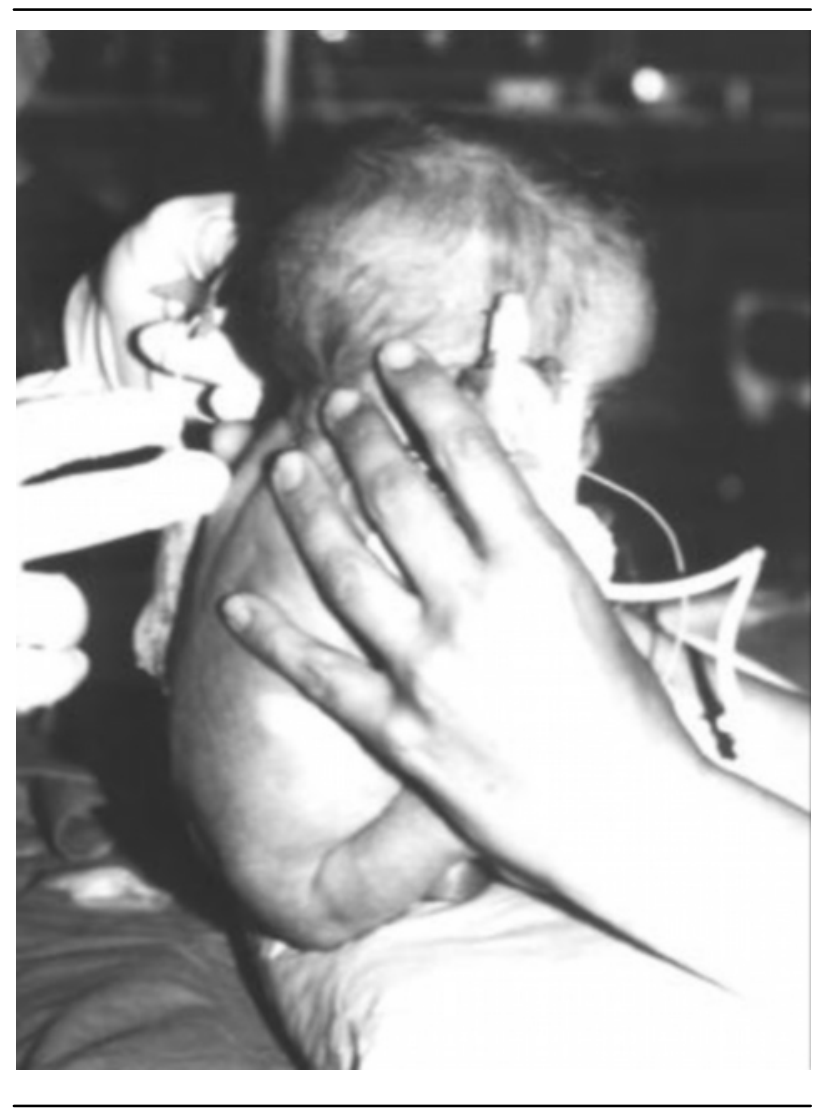

FIGURE 1 A premature infant weighing $1985 \mathrm{~g}$ placed in the seated position $10 \mathrm{~cm}$ above the level of the operating table for the induction of spinal anesthesia. The lumbar spine, hips and knees are flexed and the neck is partially extended. Fingers three to five hold the patient's chest below the axilla, and the thumb and second finger support the chin and occiput respectively.

To prevent leakage of the cream, parents and staff were instructed to avoid placing the infant supine. All patients were unpremedicated.

\section{Anesthetic technique}

Operating room temperature was maintained between $27-30^{\circ} \mathrm{C}$. Monitoring included a pulse oximeter, electrocardiogram, non-invasive blood pressure monitor and precordial stethoscope. One to $2 \mathrm{~mL}$ of $50 \%$ glucose were given per os prior to iv line insertion or SA induction. An operating theatre team member seated the infant ${ }^{15,16}$ on a folded towel $10 \mathrm{~cm}$ above the operating table (Figure 1). Gauze was placed between the buttocks to prevent perineal spillage of the antiseptic solutions. A 100\% oxygen mask was placed near the patient's face. To avoid pain on removal, the occlusive EMLA® dressing was removed using a Convacare 


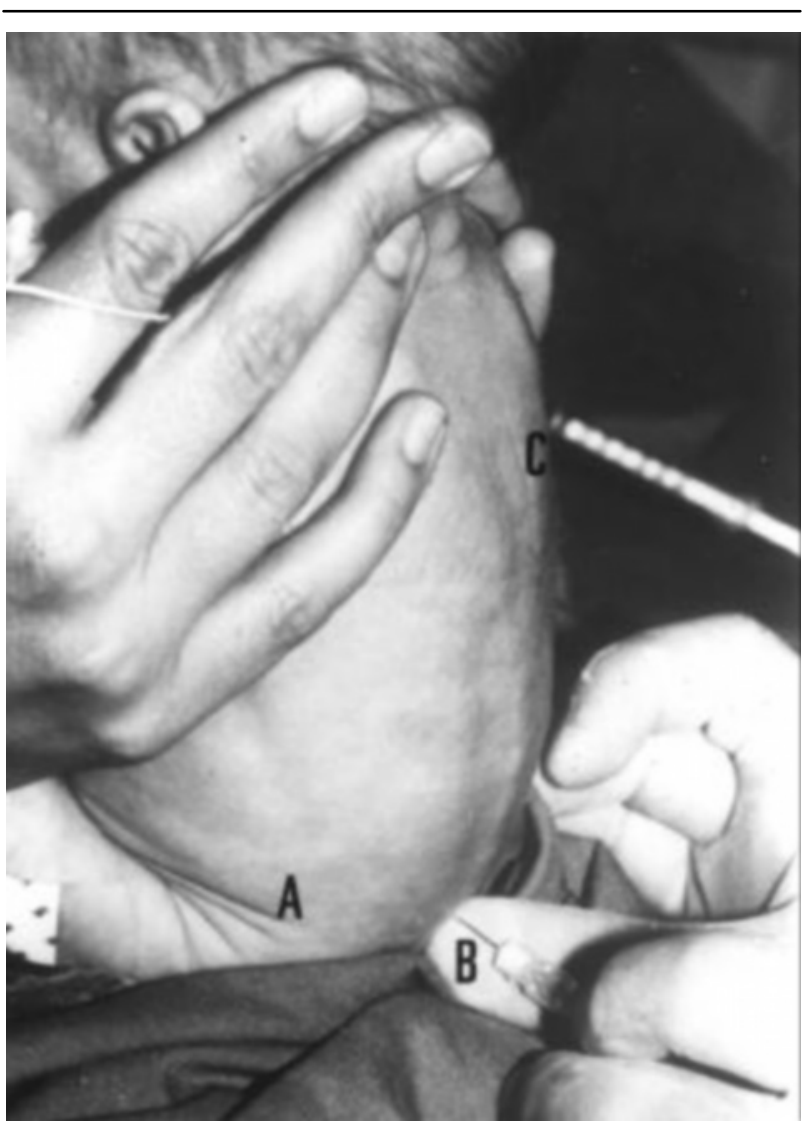

FIGURE 2 Lumbar puncture in the same patient for the induction of spinal anesthesia.

$\mathrm{A}=$ iliac crest $; \mathrm{B}=25 \mathrm{G} 2.5-\mathrm{cm}$ spinal needle; $\mathrm{C}=1-\mathrm{mL}$ syringe containing the anesthetic solution.

adhesive remover wipe (ConvaTec, Princeton, NJ, USA.) and the sterile field was prepared.

A $2.5-\mathrm{cm}, 25$-gauge Quincke spinal needle ${ }^{15}$ (Beckton Dickinson, Franklin Lakes, NJ, USA) was inserted in the midline, cephalad, in an interspace between $\mathrm{L}_{4}$ and $\mathrm{S}_{1}$ (Figure 2). This approach was adopted to avoid potential damage to the conus medullaris which terminates at $\mathrm{L}_{3}$ in infants. ${ }^{13,15}$ Subarachnoid placement, was confirmed by free flow of CSF. With the needle stabilized, the local anesthetic solution was rapidly injected without aspiration ${ }^{13,17}$ and the needle removed. All patients received 1 $\mathrm{mg} \cdot \mathrm{kg}^{-1}$ of either $0.5 \%$ hyperbaric tetracaine (a $1: 1$ mixture of $1 \%$ tetracaine and $10 \%$ glucose) or $0.5 \%$ hyperbaric bupivacaine with adrenaline 1:1000 added to either medication. ${ }^{15}$ Patients treated with diuretics received $0.8 \mathrm{mg} \cdot \mathrm{kg}^{-1}$ of local anesthetic to compensate for a potential contraction of CSF volume. The adren- aline was first drawn up in a $1-\mathrm{mL}$ syringe with detachable needle. Excess adrenaline was expelled from the syringe hub, leaving $20-40 \mu \mathrm{g}$ in the syringe. The local anesthetic solution was then added into the 1 $\mathrm{mL}$ syringe. The patient was immediately positioned supine with a $20-30^{\circ}$ head up tilt for two to three minutes, and then horizontally.

Successful SA was defined as lack of sensation to pinch at the desired sensory level and paralysis of the lower limbs. These signs, as well as defecation and diaphragmatic breathing with reduced intercostal muscle activity usually developed within one to three minutes of injection. A paracetamol suppository (20-25 mg. $\left.\mathrm{kg}^{-1}\right)$ was inserted $p r$ before the beginning of surgery, or $10-15 \mathrm{mg} \cdot \mathrm{kg}^{-1}$ of paracetamol syrup was given per os postoperatively. ${ }^{18}$ With hands restrained to avoid interference with the surgical procedure, the patient received a dummy dipped in glucose water. If the patient showed signs of unsatisfactory block, $\mathrm{N}_{2} \mathrm{O}$ was supplemented via a face mask. If this did not suffice, general anesthesia was induced with sevoflurane and $\mathrm{N}_{2} \mathrm{O}$ in oxygen via a face mask and the trachea was intubated. Anesthesia was maintained with isoflurane and $\mathrm{N}_{2} \mathrm{O}$ in oxygen. At the end of the procedure, an ilioinguinal and iliohypogastric nerve block was performed with plain bupivacaine, to a maximum dose of $2 \mathrm{mg} \cdot \mathrm{kg}^{-1}$ at a volume of $0.75-1.5 \mathrm{~mL}$ at each incision site.

The patients of the premature group were transferred to the neonatal intensive care unit (NICU) and were monitored for 'postoperative apnea' by pulse oximeter, electrocardiogram and impedance pneumography, all with alarm activation, using the Horizon 1100 (Mennen, Rehovot, Israel) and Hewlett Packard M1106 (Germany) monitors. Postoperatively, apnea is defined at our NICU as cessation of breathing for 20 sec or longer, ${ }^{19}$ hypoxemia by $\mathrm{SpO}_{2}$ lower than $92 \%$, and bradycardia below 90 beats. $\mathrm{min}^{-1}$. Infants who were 'apnea-free' for 12-24 hr were 'stepped down' to a lower level area of monitoring. Full-term infants were routinely monitored in the recovery room and thereafter in the pediatric surgical ward.

Results

Sixty-five infants originally presented for surgery. The subarachnoid space could not be identified in three premature infants and they were excluded from the present study. Fifty-five premature and former-premature (premature group), and seven full-term infants were operated on under SA (Table I).

Twenty-one of the premature infants $(38 \%)$ had coexisting disease (Table II). Fifty-three of the infants in the premature group underwent inguinal hernia repair 
TABLE I Demographic data are presented as mean \pm standard deviation of the mean and span (in brackets)

\begin{tabular}{lll}
\hline & Premature group $(n=55)$ & Full-term group $(n=7)$ \\
\hline Males : females & $42: 13$ & $5: 2$ \\
Gestational age (weeks) & $30.9 \pm 3.4(24.0-36.8)$ & $40.1 \pm 1.9(38.3-42.4)$ \\
Birth weight $(\mathrm{g})$ & $1448 \pm 628(600-2900)^{*}$ & $3181 \pm 776(2520-3900)$ \\
Postconceptional age (weeks) & $43.3 \pm 5.0(36.1-57.9)$ & $49.6 \pm 6.4(44.0-55.9)$ \\
Current weight (g) & $3261 \pm 1243(1750-6580)$ & $4313 \pm 1540(2035-6000)$ \\
Hematocrit (\%) & $30.9 \pm 5.2(22.5-42.0) \dagger$ & $37.0 \pm 6.3(28.6-47.3)$ \\
\hline
\end{tabular}

* $=40$ appropriate; 14 small and one large for gestational age; $\dagger=$ a hematocrit less than $30 \%$ was found in $23(42 \%)$, and $30-31 \%$ in nine (16\%) patients.

TABLE II Concurrent diseases

\begin{tabular}{ll}
\hline Premature and former-premature infants & $21^{*}$ \\
\hline Central nervous system & 6 \\
Cystic periventricular leukomalacia & 1 \\
Postintraventricular hemorrhage & 4 \\
Postintraventricular hemorrhage and cystic & \\
periventricular leukomalacia & 1 \\
Cardiovascular & \\
Ventricular septal defect & 9 \\
Patent foramen ovale & 1 \\
Patent ductus arteriosus & 3 \\
Patent foramen ovale and ductus arteriosus and & 2 \\
pulmonary hypertension & \\
Postsurgical closure of patent ductus arteriosus & 1 \\
Peripheral pulmonary artery stenosis and patent & 1 \\
foramen ovale & 1 \\
Pulmonary & \\
Bronchopulmonary dysplasia & 11 \\
Previous pulmonary bleeding & 9 \\
Renal and urinary tract & 2 \\
Hydronephrosis & \\
Nephrocalcinosis & 6 \\
Nephrolithiasis & 2 \\
Uretero-vesical reflux & 2 \\
Full-term infants & 1 \\
Nemaline myopathy & 1 \\
Recent bronchiolitis & 5 \\
\hline & 1 \\
\hline
\end{tabular}

* $=$ one additional premature infant had persistent jaundice with a presumed diagnosis of prenatal ischemic hepatitis.

(17 unilateral, two with orchidopexy) and two underwent pyloromyotomy. Of the seven full-term infants, five underwent inguinal hernia repair. Of these, two infants underwent urgent surgery shortly after having bronchiolitis. One with an active upper respiratory infection was operated on urgently and one infant underwent SA following parental request. One full- term infant suspected of having nemaline myopathy underwent gastrostomy and muscle biopsy and an additional infant with a provisional diagnosis of mucopolysaccharidosis underwent pyloromyotomy.

An $i v$ line was inserted prior to anesthetic induction in all infants except one in whom several $i v$ cannulation attempts before induction of SA had failed. Cannulation was performed in the lower limb after SA induction in one patient. In 13 cases blood emerged through the spinal needle. SA was performed successfully in 49 of the 55 premature $(89 \%)$ and six of the seven full-term infants $(86 \%)$. Three premature infants $(5.4 \%)$ received supplemental $\mathrm{N}_{2} \mathrm{O}$, with prompt relief of discomfort. All three had pre- and postoperative lower limb motor and sensory blockade. The infant who underwent gastrostomy showed signs of discomfort when the bowel was replaced into the abdomen prior to wound closure. Bupivacaine infiltration into the surgical wound and brief administration of $70 \%$ $\mathrm{N}_{2} \mathrm{O}$ in oxygen via face mask relieved the discomfort. Three of the premature group (5.4\%) required general anesthesia. In one of these despite an initial sensory level of $T_{3}$, severe technical problems with operating room equipment resulted in the need for general anesthesia 44 min after the beginning of pyloromyotomy. Failure of the SA in the other two premature patients occurred despite free flow of CSF through the spinal needle. However, postoperative sensory and motor blockade of the lower limbs (complete in one and incomplete in another), were observed postoperatively.

Intraoperative respiratory complications occurred in five infants. In two infants breath-holding episodes occurred within two to three minutes of injection and lasted one to two minutes (Table III). The patients were immediately placed in reverse-Trendelenburg position and bag and mask ventilation with $100 \%$ oxygen initiated until the resumption of spontaneous breathing. $\mathrm{SpO}_{2}$ below $90 \%$ was observed in two additional patients (one premature). Normal $\mathrm{SpO}_{2}$ was reestablished with $100 \%$ oxygen bag and mask assisted 
TABLE III Intra- and postoperative apnea, hypoxemia and bradycardia

\begin{tabular}{|c|c|c|c|c|c|c|c|c|}
\hline & & \multicolumn{3}{|c|}{ Intraoperative } & \multicolumn{3}{|c|}{ Postoperative } & \multirow[b]{2}{*}{$\begin{array}{l}\text { Apnea \& } \\
\text { bypoxemia }\end{array}$} \\
\hline & & Apnea & Hypoxemia & Bradycardia & Apnea & Hyрохетіа & Bradycardia & \\
\hline \multirow[t]{2}{*}{$\begin{array}{l}\text { Premature } \\
(n=55)\end{array}$} & $\begin{array}{l}\text { Number of } \\
\text { episodes }\end{array}$ & 2 & 2 & 1 & 0 & 1 & 3 & 1 \\
\hline & Treatment & $\begin{array}{l}\text { reverse - } \\
\text { Trendelenburg, } \\
\text { mask ventilation }\end{array}$ & $\begin{array}{l}\text { l - mask } \\
\text { ventilation } \\
\text { l - spontaneous } \\
\text { recovery }\end{array}$ & atropine & - & $\begin{array}{l}\text { supplemental } \\
\text { oxygen }\end{array}$ & $\begin{array}{l}\text { spontaneous } \\
\text { recovery }\end{array}$ & $\begin{array}{l}\text { tactile } \\
\text { stimulation, } \\
\text { supplemental } \\
\text { oxygen }\end{array}$ \\
\hline \multirow[t]{2}{*}{$\begin{array}{l}\text { Full-term } \\
(n=7)\end{array}$} & $\begin{array}{l}\text { Number } \\
\text { of episodes }\end{array}$ & 0 & 0 & 0 & 0 & 1 & 0 & 0 \\
\hline & Treatment & - & - & - & - & $\begin{array}{l}\text { supplemental } \\
\text { oxygen }\end{array}$ & - & - \\
\hline
\end{tabular}

ventilation in one infant, and returned spontaneously to normal in the other. A fifth patient developed bradycardia without apnea or hypoxemia 13 min after induction that was resistant to tactile stimulation but responded to $i v$ atropine. In all other infants, $\mathrm{SpO}_{2}$ was $95 \%$ (one patient) or higher, and heart rate was 107 or higher.

Postoperative apnea was diagnosed in five of the premature group (9.1\%). Hypoxemia (one infant) and apnea and hypoxemia (one infant) occurred upon arrival to NICU. Of the three premature infants who developed bradycardia, one had received iv opioids several hours previously. Hypoxemia was noted in one full-term infant at the end of pyloromyotomy when the sensory level was at $\mathrm{T}_{5}$ and resolved with supplemental oxygen. None of the infants who received $\mathrm{N}_{2} \mathrm{O}$ supplementation experienced postoperative apnea. One premature infant with no previous history of wheezing developed a postoperative expiratory wheeze after a successful SA and was treated with inhaled bronchodilators.

Discussion

The objectives of SA in premature and former-premature infants are analgesia and muscle relaxation with minimal physiological disturbance, rapid recovery and prevention of complications associated with prematurity or its treatment. ${ }^{7}$ The risk of 'postoperative apnea' is lower with SA than with general anesthe$\operatorname{sia}^{8,10,17}$ as long as sedatives or general anesthetics are not administered. ${ }^{8,17} \mathrm{SA}$ is therefore the anesthetic of choice at our institution in premature and former-premature infants for short abdominal surgical procedures and hence, for ethical reasons, we did not design a comparative study. All our premature patients had two out of the three risk factors associated with 'postoperative apnea': low gestational (under 37 weeks) ${ }^{7}$ and postconceptional age (under 60 weeks). ${ }^{1,7,11}$ The third risk factor, anemia ${ }^{7,9}$ or borderline hematocrit was present in about $50 \%$ (Table I). Five full-term infants with co-existing disease underwent SA in order to avoid potential risks of general anesthesia. ${ }^{20,21}$

Our technique is to sit the patient for LP, flex the lumbar spine, hips and knees, partially extend the neck and support the head. ${ }^{15}$ The sitting patient is less mobile, ${ }^{16}$ bony landmarks are more prominent and the CSF hydrostatic pressure increases, thus allowing faster detection of CSF. ${ }^{15}$ Head flexion may lead to hypoventilation. ${ }^{15}$ Furthermore, sitting the patient may reduce the fall in $\mathrm{PO}_{2}$ usually seen during LP. ${ }^{1} 6$

We advise sitting the patient above the level of the operating table on folded towels. If the patient is seated directly on the table, the needle hub may be too close to the table making syringe attachment difficult. Alternatively, the syringe may be connected to the needle via an extension tube filled with the anesthetic solution, or when CSF appears the patient may be leaned forward to allow syringe attachment (Navil F Sethna, MD, Children's Hospital, Boston, USA, personal communication). A styletted needle should be used to prevent the rare complication of intraspinal epidermoid tumour due to seeding of epidermal cells. ${ }^{15}$ We use 2.5 or 5-cm 25-gauge spinal needles, but other diameters may be used. $8,13,15,17$ We do not try to aspirate CSF through the spinal needle as this can lead to needle displacement from the subarachnoid space. Contrary to others, we do not delay needle removal, a practice advocated to prevent fluid loss in the track. ${ }^{17}$ Nevertheless, our practice is associated with at least the same success 
rate of SA reported by others. ${ }^{10,22}$ In 13 cases blood emerged through the spinal needle. Based on our experience, we advise not to withdraw the needle since CSF may still appear. CSF appearance may be accelerated by absorption of the blood from the needle hub by gauze rolled into a cone. If this does not happen, the needle should be withdrawn slowly until CSF appears or until the needle is completely withdrawn and another LP is attempted.

Immediately after subarachnoid injection the patient is placed in a $20-30^{\circ}$ reverse-Trendelenburg position for two to three minutes to prevent a higher than desirable motor block. However, if this position is maintained longer, the sensory level may be inadequate.

Higher doses of local anesthetics per kilogram body weight $\left(1 \mathrm{mg} \cdot \mathrm{kg}^{-1}\right)$ are required in infants compared with adults and may be related to the larger volume of distribution (CSF) (4vs $2 \mathrm{~mL} \cdot \mathrm{kg}^{-1}$ in adults) or to the relatively increased surface area of the spinal cord and nerve roots. ${ }^{15,17}$ While lower doses may result in a low sensory level or patchy anesthesia, ${ }^{10,15,17,22}$ higher doses usually cause loss of lower intercostal muscle activity as evidenced by reduction of chest wall expansion and paradoxical breathing. ${ }^{23}$ There is an increased reliance on the diaphragm for tidal breathing ${ }^{15}$ as evidenced by increased abdominal excursion. ${ }^{2}{ }^{3}$ While $1 \mathrm{mg} \cdot \mathrm{kg}^{-1}$ of tetracaine or bupivacaine usually results in a sensory level of $\mathrm{T}_{2}-\mathrm{T}_{4},{ }^{15}$ higher levels may be observed. ${ }^{24}$ The motor level is usually two to three segments lower than the sensory level. ${ }^{15,23}$ Despite the high anesthetic level, hemodynamic and respiratory stability are maintained. ${ }^{15,22-24}$ This is explained by less dependence on vasomotor tone in newborns ${ }^{15}$ and a compensatory decrease in vagal activity. ${ }^{24}$ Caudal anesthesia may also be administered to premature infants. We prefer, how ever, the use of SA because of its faster onset, the profound sensory blockade and flaccid paralysis, the smaller local anesthetic dose requirements and CSF flow confirming correct needle placement. The disadvantages of SA compared with caudal anesthesia include its shorter duration, greater technical difficulties and the impossibility to use a catheter to prolong anesthetic duration.

Almost $90 \%$ of our patients had satisfactory SA with no need for anesthetic or analgesic supplementation, compared with $79 \%^{22}$ and $67 \%^{10}$ in previous reports. Our higher success rate may be related to a higher dose of local anesthetic ( 1 vs $0.5^{22}$ and $0.6^{10} \mathrm{mg} \cdot \mathrm{kg}^{-1}$ ).

The much shorter duration of SA in neonates compared to adults may be related to the higher volume of distribution and increased cardiac output. This results in faster drug distribution, uptake and elimination of the drug. ${ }^{13,15,17}$ Motor level regression is approximately five times faster than in adults. Adding epinephrine to tetracaine increases the block duration by an average of $32 \% .{ }^{13}$ After the onset of SA, infants who are restless during the LP become quiet and some fall asleep. ${ }^{17}$

Intraoperative complications attributed to $\mathrm{SA}$ in infants are uncommon and usually are not reported. Apnea, hypoxemia or bradycardia may be related to prematurity, pain during LP or hypoventilation due to a 'high spinal'. ${ }^{23}$ 'High spinal' occurs in $3-25 \%$ of infants, ${ }^{17,22,25}$ and bradycardia or hypoxemia in $2.3 \% .^{22}$ In our series, despite the presence of co-existing disease in $38 \%$ of our patients, intraoperative complications were few and treated easily (Table III). We speculate that the episode of apnea that occurred in a patient on diuretic therapy, may be the result of a contracted CSF volume, decreasing the volume of distribution of the local anesthetic and increasing the level of anesthesia. The anesthetic dose may be reduced to $0.8 \mathrm{mg} \cdot \mathrm{kg}^{-1}$ in patients who receive diuretics (Navil F Sethna, MD, Children's Hospital, Boston, USA, personal communication).

We have no explanation for the hypoxemia at the end of pyloromyotomy in a full-term infant with a block to level $\mathrm{T}_{5}$. Hypoventilation secondary to the metabolic alkalosis of pyloric stenosis may have been a contributory factor.

The most common postoperative complication is 'postoperative apnea'. It results from the combination of prematurity, anesthetic agent exposure ${ }^{1,8}$ and increased endogenous opioid production in the first 72 hr postoperatively. ${ }^{1}$ Its three components (breath-holding, hypoxemia and bradycardia) may occur simultaneously or separately; their order of appearance is unpredictable $7,10,11,22$ and most terminate spontaneously. ${ }^{7}$ Approximately $70 \%$ of the breath-holding episodes are 'central' in origin, about $10 \%$ are 'obstructive' and $30 \%$ are combined. ${ }^{7}$ Most episodes appear within the first few hours following surgery. The first episode usually arises within the first 12 postoperative hours but may appear later. ${ }^{1,7,15}$ Therefore, premature and formerpremature infants are closely monitored postoperatively and only if 'apnea-free' for 12-24 hr, are they transferred to a step-down unit.

The incidence of 'postoperative apnea' was 9.1\% (five of 55). Higher ${ }^{1}$ and lower 8,17,22 rates of 'postoperative apnea' have been reported previously following SA. A higher rate of postoperative apnea may have been demonstrated had we analyzed monitor-tracing recordings $^{7,8}$ or used nasal airflow thermistors. ${ }^{10,11}$ Nevertheless, this incidence may be related to the state of prematurity rather than to SA or surgery, since the incidence of pre-operative hypoxemia and apnea in this patient population is $33 \%$ and $17-28 \%$, respectively. ${ }^{10}$

Aseptic meningitis, a rare complication of $S A,{ }^{26}$ was not observed in our study. The incidence of postdural 
puncture headache in infants is unknown, possibly due to their inability to verbalize pain, their natural horizontal position and a lack of documentation. ${ }^{15}$

It may be argued that the combined dose of local anesthetics for SA $\left(1 \mathrm{mg} \cdot \mathrm{kg}^{-1}\right)$ and for ilioinguinaliliohypogastric nerve block $\left(2 \mathrm{mg} \cdot \mathrm{kg}^{-1}\right)$ may be too high for young infants because of concerns of local anesthetic toxicity. However, the first dose was administered before the beginning of surgery and the second at its end. Moreover, systemic absorption of bupivacaine after peripheral nerve or field block is slow while that after SA is quick in young infants. ${ }^{15,17}$ Therefore, we assumed that our patients would not be put under such a risk. In fact, no case of local anesthetic toxicity was observed in any of our patients.

Finally, application of EMLA ${ }^{\circledR}$ cream in infants younger than three months has been questioned because of concerns of methemoglobinemia. Single applications have not been shown to cause clinically significant methemoglobinemia in pre-term or fullterm neonates. ${ }^{27-29}$ This may be due to the use of small doses ${ }^{28,29}$ short duration of application ${ }^{28}$ and absence of other risk factors (e.g., first few days of life in patients less than 32 weeks of gestational age, anemia and the concomitant administration of paraceta$\mathrm{mol}$ ) for methemoglobinemia. ${ }^{28,29}$ While paracetamol administration and anemia were common in our patients, clinical signs of methemoglobinemia were not observed (methemoglobin levels were not measured). However, our youngest patient was 36 weeks postconceptional age and only single small doses of EMLA® were applied. Although methemoglobin levels were not measured in this study, in no case were clinical signs of methemoglobinemia present.

In conclusion, SA for premature and former-premature infants, who have co-existing disease and risk factors for postoperative apnea, is an effective, easy and safe technique. Careful perioperative monitoring, a relatively high dose of hyperbaric local anesthetic solution with adrenaline, and appropriate patient positioning during LP and immediately following injection of the drug are important for the safe conduct of SA in young infants.

Acknowledgement

Dr. Navil Sethna, for innovating and encouraging the use of spinal anesthesia in infants.

References

1 Kurth CD, Spitzer AR, Broennle AM, Downes JJ. Postoperative apnea in preterm infants. Anesthesiology 1987; 66: 483-8.

2 Rajput A, Gauderer $M W L$, Hack M. Inguinal hernias in very low birth weight infants: incidence and timing of repair. J Pediatr Surg 1992; 27: 1322-4.

3 Harper RG, Garcia A, Sia C Inguinal hernia: a common problem of premature infants weighing 1,000 grams or less at birth. Pediatrics $1975 ; 56$ : 112-5.

4 Puri P, Guiney EJ, O'Donnell B. Inguinal hernia in infants: the fate of the testis following incarceration. J Pediatr Surg 1984; 19: 44-6.

5 Krieger NR, Shochat SJ, McGowan V, Hartman GE. Early hernia repair in the premature infant: long-term follow-up. J Pediatr Surg 1994; 29: 978-82.

6 Rescorla FJ, Grosfeld JL. Inguinal hernia repair in the perinatal period and early infancy: clinical considerations. J Pediatr Surg 1984; 19: 832-7.

7 Coté CJ, Zaslavsky A, Downes JJ, et al. Postoperative apnea in former preterm infants after inguinal herniorrhaphy. A combined analysis. Anesthesiology 1995; 82: 809-22.

8 Welborn LG, Rice LJ, Hannallah RS, Broadman LM, Ruttimann UE, Fink $R$ Postoperative apnea in former preterm infants. Prospective comparison of spinal and general anesthesia. Anesthesiology 1990; 72: 838-42.

9 Welborn LG, Hannallah RS, Luban NLC, Fink R, Ruttimann UE. Anemia and postoperative apnea in former preterm infants. Anesthesiology 1991; 74: 1003-6.

10 Krane EJ, Haberkern CM, Jacobson LE. Postoperative apnea, bradycardia, and oxygen desaturation in formerly premature infants: prospective comparison of spinal and general anesthesia. Anesth Analg 1995; 80: 7-13.

11 Malviya S, Swartz J, Lerman J. Are all preterm infants younger than 60 weeks spostconceptual age at risk for postanesthetic apnea? Anesthesiology 1993; 78: 1076-81.

12 Fisher DM. When is the ex-premature infant no longer at risk for apnea? (Editorial). Anesthesiology 1995; 82: 807-8.

13 Abajian JC, Mellish P, Browne AF, Perkins FM, Lambert DH, Mazuzan JE Jr. Spinal anesthesia for surgery in the high-risk infant. Anesth Analg 1984; 63: 359-62.

14 Escobedo $M B$, Gonzales $A$ Bronchopulmonary dysplasia in the tiny infant. Clin Perinatol 1986; 13: 315-26.

15 Sethna NF, Berde CB. Pediatric regional anesthesia. In: Gregory GA (Ed.). Pediatric Anesthesia, 3rd ed. New York: Churchill Livingstone Inc., 1994: 281-317.

16 Gleason CA, Martin RJ, Anderson JV, Carlo WA, Sanniti KJ, Fanaroff $A A$ Optimal position for a spinal tap in preterm infants. Pediatrics 1983; 71: 31-5.

17 Webster AC, McKishnie JD, Kenyon CF, Marshall DG. Spinal anaesthesia for inguinal hernia repair in highrisk neonates. Can J Anaesth 1991; 38: 281-6.

18 van Lingen RA, Denium JT, Quak JME, et al. 
Pharmacokinetics and metabolism of rectally administered paracetamol in preterm neonates. Arch Dis Child Fetal Neonatal Ed 1999; 80: F59-63.

19 Eichenwald EC, Aina A, Stark AR. Apnea frequently persists beyond term gestation in infants delivered at 24 to 28 weeks. Pediatrics 1997; 100: 354-9.

20 Shenkman Z, Sheffer O, Erez I, Litmanowitc I, Jedeikin $R$. Spinal anesthesia for gastrostomy in an infant with nemaline myopathy. Anesth Analg 2000; 91: 858-9.

21 Diaz JH, Belani KG. Perioperative management of children with mucopolysaccharidoses. Anesth Analg 1993; 77: 1261-70.

22 Frumiento C, Abajian CJ, Vane DW. Spinal anesthesia for preterm infants undergoing inguinal hernia repair. Arch Surg 2000; 135: 445-51.

23 Pascucci RC, Hershenson MB, Sethna NF, Loring SH, Stark $A R$. Chest wall motion of infants during spinal anesthesia. J Appl Physiol 1990; 68: 2087-91.

24 Oberlander TF, Berde CB, Lam KH, Rappaport LA, Saul JP. Infants tolerate spinal anesthesia with minimal overall autonomic changes: analysis of heart rate variability in former premature infants undergoing hernia repair. Anesth Analg 1995; 80: 20-7.

25 Gerber ACH, Baitella LC, Dangel PH. Spinal anaesthesia in former preterm infants. Paediatr Anaesth 1993; 3: 153-6.

26 Easley RB, George R, Connors D, Tobias JD. Aseptic meningitis after spinal anesthesia in an infant. Anesthesiology 1999; 91: 305-7.

27 Prevention and management of pain and stress in the neonate. A joint statement of the Fetus and Newborn Committee, Canadian Paediatric Society, and Committee on Fetus and Newborn, Committee on drugs, Section on Anesthesiology and Section on Surgery, America, Academy of Pediatrics. Paediatrics \& Child Health 2000; 5: 31-8.

28 Sethna N. Regional anesthesia and analgesia. Semin Perinatol 1998; 22: 380-9.

29 Gourrier E, Karoubi P, El Hanache A, Merbouche S, Mouchnino $G$, Leraillez J. Use of EMLA ${ }^{\circledR}$ cream in a department of neonatology. Pain 1996; 68: 431-4. 